\title{
Article \\ Common-Mode Voltage Reduction in Capacitive Sensing of Biosignal Using Capacitive Grounding and DRL Electrode
}

\author{
Tadeas Bednar, Branko Babusiak* D, Michal Labuda, Milan Smetana and Stefan Borik
}

check for updates

Citation: Bednar, T.; Babusiak, B.; Labuda, M.; Smetana, M.; Borik, S. Common-Mode Voltage Reduction in Capacitive Sensing of Biosignal Using Capacitive Grounding and DRL Electrode. Sensors 2021, 21, 2568. https://doi.org/10.3390/s21072568

Academic Editor: Jungsuk Kim

Received: 4 February 2021

Accepted: 5 April 2021

Published: 6 April 2021

Publisher's Note: MDPI stays neutral with regard to jurisdictional claims in published maps and institutional affiliations.

Copyright: (c) 2021 by the authors. Licensee MDPI, Basel, Switzerland. This article is an open access article distributed under the terms and conditions of the Creative Commons Attribution (CC BY) license (https:// creativecommons.org/licenses/by/ $4.0 /)$.
Department of Electromagnetic and Biomedical Engineering, University of Zilina, 01026 Zilina, Slovakia; tadeas.bednar@feit.uniza.sk (T.B.); michal.labuda@feit.uniza.sk (M.L.); milan.smetana@feit.uniza.sk (M.S.); stefan.borik@feit.uniza.sk (S.B.)

* Correspondence: branko.babusiak@feit.uniza.sk

\begin{abstract}
A capacitive measurement of the biosignals is a very comfortable and unobtrusive way suitable for long-term and wearable monitoring of health conditions. This type of sensing is very susceptible to noise from the surroundings. One of the main noise sources is power-line noise, which acts as a common-mode voltage at the input terminals of the acquisition unit. The origin and methods of noise reduction are described on electric models. Two methods of noise removal are modeled and experimentally verified in the paper. The first method uses a passive capacitive grounding electrode, and the second uses an active capacitive Driven Right Leg (DRL) electrode. The effect of grounding electrode size on noise suppression is experimentally investigated. The increasing electrode area reduces power-line noise: the power of power-line frequency within the measured signal is $70.96 \mathrm{~dB}, 59.13 \mathrm{~dB}$, and $43.44 \mathrm{~dB}$ for a grounding electrode area of $1650 \mathrm{~cm}^{2}, 3300 \mathrm{~cm}^{2}$, and $4950 \mathrm{~cm}^{2}$, respectively. The capacitive DRL electrode shows better efficiency in common-mode noise rejection than the grounding electrode. When using an electrode area of $1650 \mathrm{~cm}^{2}$, the DRL achieved $46.3 \mathrm{~dB}$ better attenuation than the grounding electrode at power-line frequency. In contrast to the grounding electrode, the DRL electrode reduces a capacitive measurement system's financial costs due to the smaller electrode area made of the costly conductive textile.
\end{abstract}

Keywords: capacitive sensing; common-mode noise; noise suppression; grounding; DRL

\section{Introduction}

Bioelectrical signals such as electrocardiography (ECG), electromyography (EMG), and electroencephalography (EEG) are diagnostic methods that are frequently used in medicine to monitor the health and diagnose various diseases. The frequency ranges of these signals are given in Table 1 [1]. Traditional monitoring systems use electrodes (most often $\mathrm{Ag} / \mathrm{AgCl}$ ) placed directly on the measured subject's skin. An electrically conductive gel in liquid or solid form decreases transient resistance between the electrode and the skin. The electrode-gel combination provides a relatively good conductive contact (resistance < $10 \mathrm{k} \Omega$ ) and signal transmission between the electrode and the patient's body. Nevertheless, when wet electrodes are used, the conductive gel dries out during long-term measurements, and the electroconductive gel can cause skin irritation [2]. The use of measurement systems using wet electrodes is not suitable for unobtrusive and long-term sensing because of the measured subject's discomfort. An alternative to such electrodes is the so-called dry electrodes by which the signal is sensed without direct contact with the patient skin. This kind of electrode can be engaged in chairs or beds. Electrodes with integrated electronics, called active electrodes (AE), are commonly used for this purpose. Such electrodes can be applied directly to the body, or the signal is sensed through the wearable garment. It is advantageous to use electrodes without direct skin contact to create a system for long-term and comfortable monitoring of biosignals. 
Table 1. Frequency ranges of biosignals. Reprinted with permission from ref. [1]. Copyright 2017 Elsevier B.V.

\begin{tabular}{cc}
\hline Biosignal & Frequency Bandwidth [Hz] \\
\hline ECG-ambulatory monitoring & $0.67-40$ \\
ECG-diagnostic purposes & $0.05-150$ \\
EEG & $0.1-100$ \\
EMG & $10-2000$ \\
\hline
\end{tabular}

The AEs with an integrated operational amplifier (OA) are commonly used because they form an impedance barrier between the electrode-skin interface and the signal processing circuits. Sensing using active electrodes leads to certain problems caused by the high impedance of capacitive electrodes in the frequency range of bioelectric signals (Table 1). The electrical schematic of the active electrode, the sensing surface's size, material, and the dielectric between the electrode and the skin are essential for capacitive electrodes. In Asl et al. [3], the transfer properties of active electrodes were compared using different sensing surface areas $\left(64 \mathrm{~cm}^{2}, 32 \mathrm{~cm}^{2}, 16 \mathrm{~cm}^{2}\right)$. The work by Babusiak et al. [4] pointed out the different transfer properties of active electrodes using electrically conductive textile materials made of Shieldex and Elitex fibers. A comparison of three flexible capacitive electrodes was presented by Peng et al. [5]. They simultaneously measured the ECG signal using active electrode sensing surfaces made of conductive textile, copper foil tape, and a flexible printed circuit. In Rachim et al. [6], a capacitive electrode's transmission properties were compared while acquiring an ECG signal through the different dielectric thicknesses. They compared the transmission characteristics for cotton with a thickness of $0.1 \mathrm{~mm}$ to $3 \mathrm{~mm}$.

Another issue concerning active electrodes is the common-mode voltage $(50 \mathrm{~Hz}$ signal for Europe, Africa, Asia, and Australia or $60 \mathrm{~Hz}$ for North America and North Latin America) sensed along with the useful signal. In standard sensing, the suppression of this signal is realized by connecting the ground of the system to the patient's body using a conventional $\mathrm{Ag} / \mathrm{AgCl}$ electrode or by active rejection using a DRL (Driven Right Leg) circuit [7]. The use of DRL electrode presents the Common-Mode FeedBack (CMFB) method, where the common-mode output voltage of AEs is inverted, gain and fed back to the subject. The use of a conventional electrode connected to the body is ruled out in capacitive non-intrusive monitoring. A capacitive electrode must also replace the standard ground electrode. The capacitively coupled electrodes also have a higher impedance (at a mains frequency of $50 \mathrm{~Hz} / 60 \mathrm{~Hz}$ ) than conventional ones. One way to reduce the impedance of such an electrode is to increase its area, which increases the cost of the measuring system itself because the conductive fibers are relatively expensive. In work of Lim et al. [8], the impact of various DRL circuit gains on the common-mode voltage was examined. Another option to reduce the common-mode voltage in measured data is the Common-Mode FeedForward (CMFF) technique. This method is based on the compensation of the common-mode signal at both $\mathrm{AE}$ inputs before amplification. This kind of method was used, for example, in the works of Xu et al. $[9,10]$. The disadvantage of this method type is a requirement of a specialized circuit design. The next option to suppress common-mode voltage is embedding the additional notch filter inside the acquisition unit [11]. This solution's disadvantage rests in the signal saturation at the input of active electrodes in case of the high value of common-mode voltage without using the third noise suppression electrode.

For this reason, we decided to create models describing the interference of a capacitively coupled monitoring system with a power-line, which is used to examine the suppression of the common-mode voltage by grounding electrode. In this work, we compare the properties of a system using passive and active suppression of power-line interference. We also created a measurement system to compare the signal sensed by both methods at different sizes of ground electrodes. 


\section{Materials and Methods}

Figure 1 shows the schematic of the active electrode with OA in the configuration as a voltage buffer, where $C_{\mathrm{e}}$ represents the capacitance between the sensing area of $\mathrm{AE}$ and the subject skin. In some studies, parallel leakage resistance is considered, but it is commonly neglected because of its high value [12]. The real OA has finite input impedance $(\approx \mathrm{T} \Omega)$, unlike the ideal OA, so the bias current flows through OA's input. When the $C_{\mathrm{e}}$ capacitance is connected to this input, it is necessary to create an electrical path for bias current to prevent charging of the connected capacitor. The $R_{\mathrm{B}}$ bias resistor is commonly used for this purpose. The input capacitance of $\mathrm{AE}$ also must be considered during the design and construction of AE. The parasitic capacitance is shown as $C_{\mathrm{pi}}$ in Figure 1 . The complex transfer characteristic is stated as

$$
G(j \omega)=\frac{j \omega C_{\mathrm{e}} R_{\mathrm{B}}}{1+j \omega R_{\mathrm{B}}\left(C_{\mathrm{e}}+C_{\mathrm{pi}}\right)} .
$$

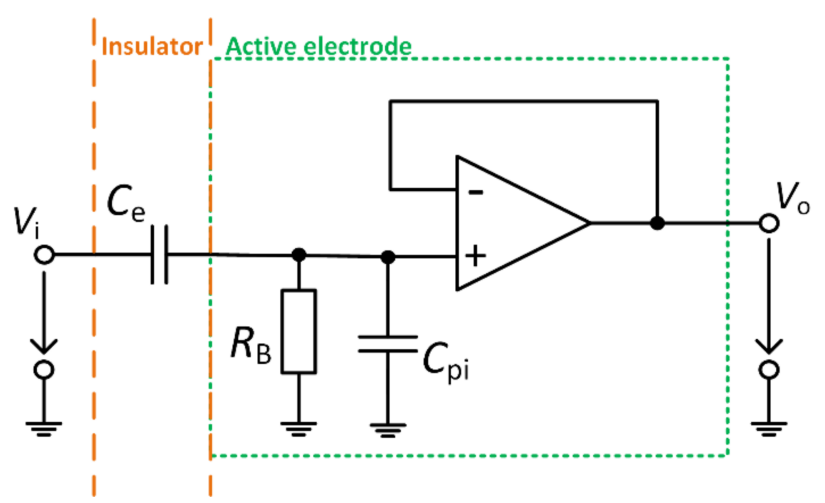

Figure 1. Model of the active electrode.

As we can see, the $C_{\text {pi }}$ parasitic capacitance decreases the gain of the active electrode, and the effect of the parasitic capacitance has to be eliminated. A few commonly used methods for parasitic capacitance cancelation exist, for example, neutralization circuit or using of guard layer [13-16]. When using the assumption of neglected parasitic capacitance, the transfer characteristic can be determined as

$$
G(j \omega)=\frac{j \omega C_{\mathrm{e}} R_{\mathrm{B}}}{1+j \omega R_{\mathrm{B}} C_{\mathrm{e}}} .
$$

The combination of $C_{\mathrm{e}}$ and $R_{\mathrm{B}}$ creates the high-pass filter at the beginning of the voltage follower, whose $f_{\mathrm{c}}$ corner frequency can be calculated according to the Equation:

$$
f_{\mathrm{c}}=\frac{1}{2 \pi R_{\mathrm{B}} C_{\mathrm{e}}} .
$$

In general, the capacitive electrodes have a sensing area in the range of a few $\mathrm{cm}^{2}$, e.g., the work by Bednár et al. [17] presents the sensing area of $16 \mathrm{~cm}^{2}$, and the work by Hou et al. [18] uses an area of $12.56 \mathrm{~cm}^{2}$. Assuming such size of the sensing surface (assumption with clothes with thickness less than a few $\mathrm{mm}$ ), the $C_{\mathrm{e}}$ capacitance between the skin's surface and the electrode reaches a value range from $10 \mathrm{pF}$ to a few hundreds of $\mathrm{pF}$. This fact implies that the high-value bias resistor $(\mathrm{G} \Omega$ ) must be used to acquire bioelectrical signals in the required frequency bandwidth. The $R_{\mathrm{B}}$ bias resistor dependent transfer characteristic, with the assumption of $C_{\mathrm{e}}=150 \mathrm{pF}$ (also used in work of Babusiak et al. [4]), is shown in Figure 2. This figure shows that the usage of capacitively coupled electrodes is not appropriate for the measurement of diagnostic ECG. However, they can monitor ambulatory ECG [19] or surface EMG [20]. The figure also shows that the $R_{\mathrm{B}}$ bias resistor 
value of $2 \mathrm{G} \Omega$ is sufficient for monitoring ambulatory ECG while using the capacitive coupling of $150 \mathrm{pF}$.

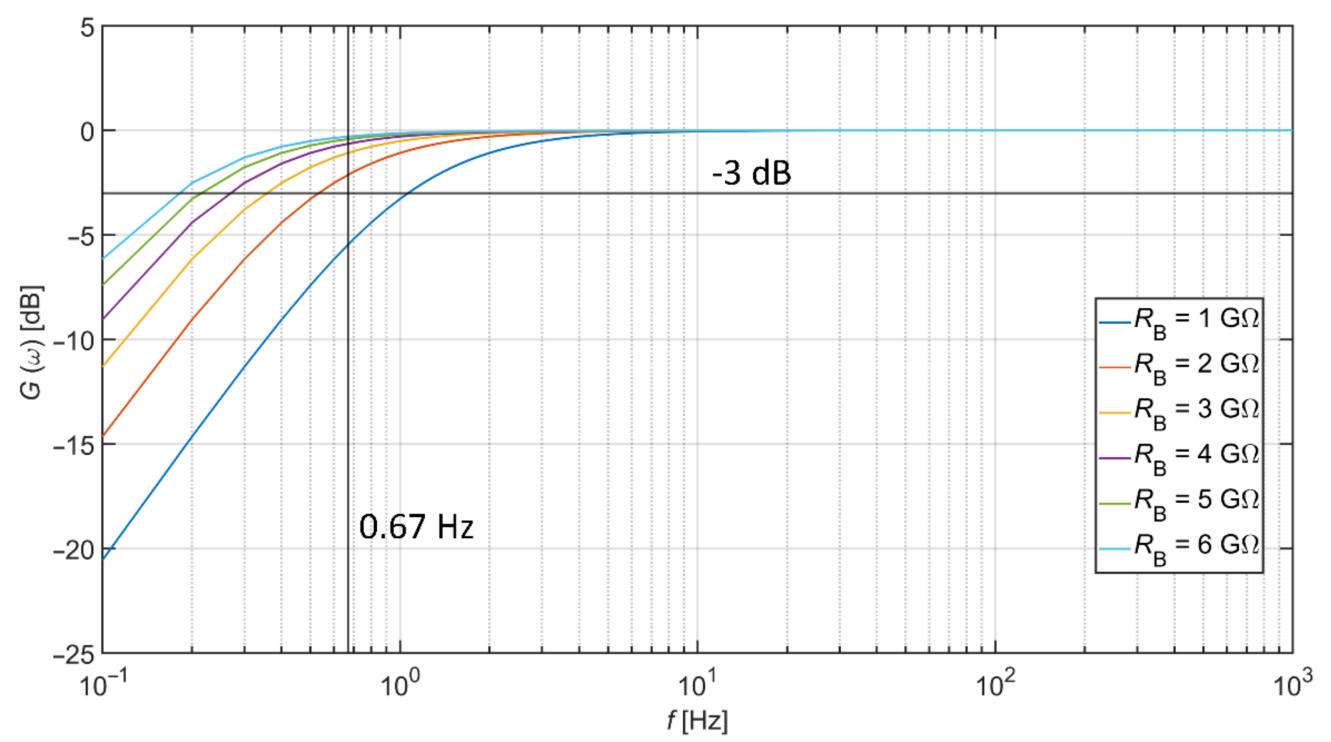

Figure 2. Transfer characteristics according to different values of $R_{\mathrm{B}}$.

The active electrode with integrated circuit AD8642 (Analog Devices, Inc., Norwood, MA, USA) with two OAs was designed for our measurements. Both OAs were configurated as voltage buffers. The first one was used as an impedance barrier (Figure 1), and the second one creates a guard layer to reduce the effect of parasitic input capacitance. The designed AE was constructed as 3-layer PCB (Printed Circuit Board). The bottom layer represents the sensing layer, the middle layer represents the guard, and the top layer includes integrated OAs with a bias resistor and ground plane around components.

The same electrode was presented and analyzed in detail by Bednar et al. [16] Figure $3 a$ represents the schematic and layers disposition of AE Figure $3 b$ shows the physical construction of AE with a sensing area of $16 \mathrm{~cm}^{2}$. The impact of the active electrode guard layer in capacitively coupled measurements was already presented by Bednar et al. [16]. In this work, the improvement of the $\mathrm{AE}^{\prime}$ 's transfer characteristic was confirmed due to the use of the guard layer. Moreover, it was proved that the guard layer increases the total CMRR (Common Mode Rejection Ratio) of the acquisition system.

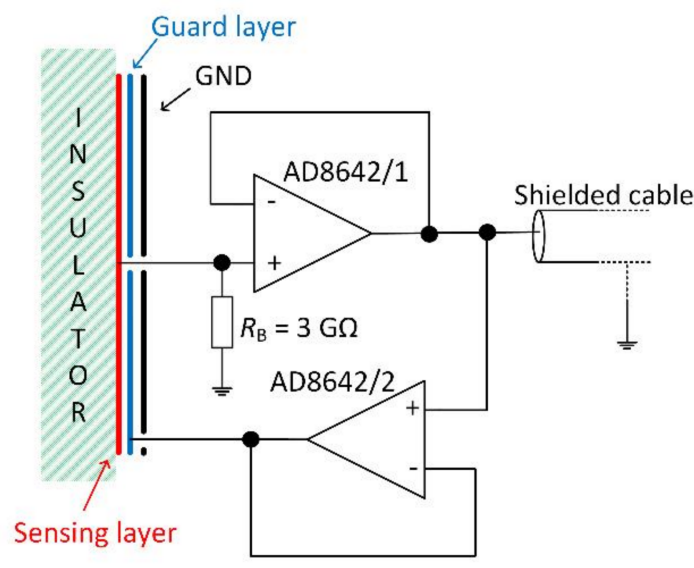

a)

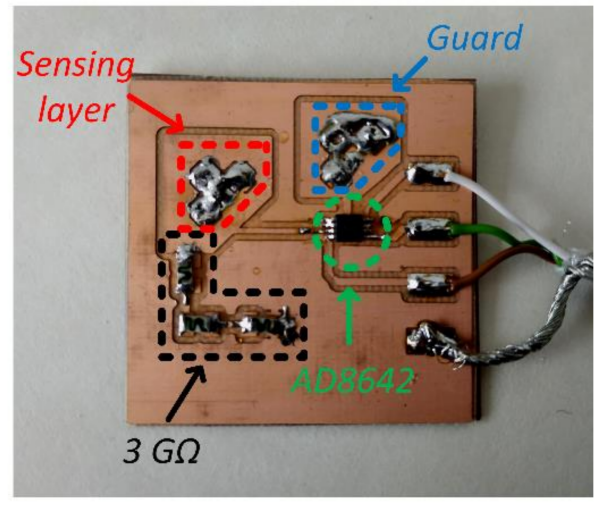

b)

Figure 3. Schematic (a) and design (b) of the constructed active electrode. Reprinted with permission from ref. [16]. Copyright 2019 Elsevier B.V. 
Comparison of transfer characteristics with connected and unconnected guard layer is shown in Figure 4. The cotton with a thickness of $0.45 \mathrm{~mm}$ is used as a dielectric material, and the pressure of $1.23 \mathrm{kPa}$ was applied to the electrode. The comparison shows that the involvement of the guard layer improves the transfer properties of AE. For example, the gain difference of the unguarded and guarded electrodes is $6.98 \mathrm{~dB}$ at $10 \mathrm{~Hz}$.

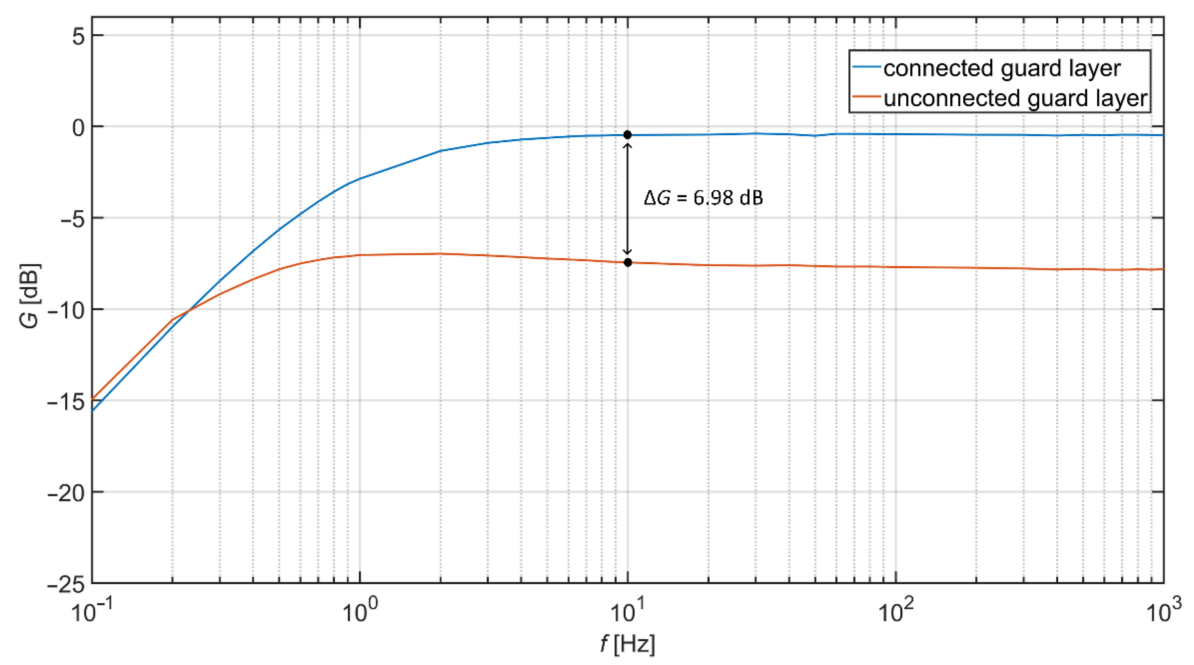

Figure 4. Measured transfer characteristics.

The electrical model of the acquisition system for capacitive measurement is shown in Figure 5. The model is based on similar models presented in $[11,21,22]$. The parasitic capacitances between the power-line, measured subject, and the device are also considered. The $V_{\mathrm{P}}$ represents the power-line source, $C_{\mathrm{P}}$ capacitance between the power-line and the measured subject, $C_{\mathrm{B}}$ capacitance between the subject and the power-line ground, and $C_{\mathrm{S}}$ capacitance between the ground of the acquisition system and the power-line ground. Values of these capacitances are listed in Table $2[11,21,22]$. These values are indicative, and they depend on the methodology of measurement, environment, and parameters of the measuring device.

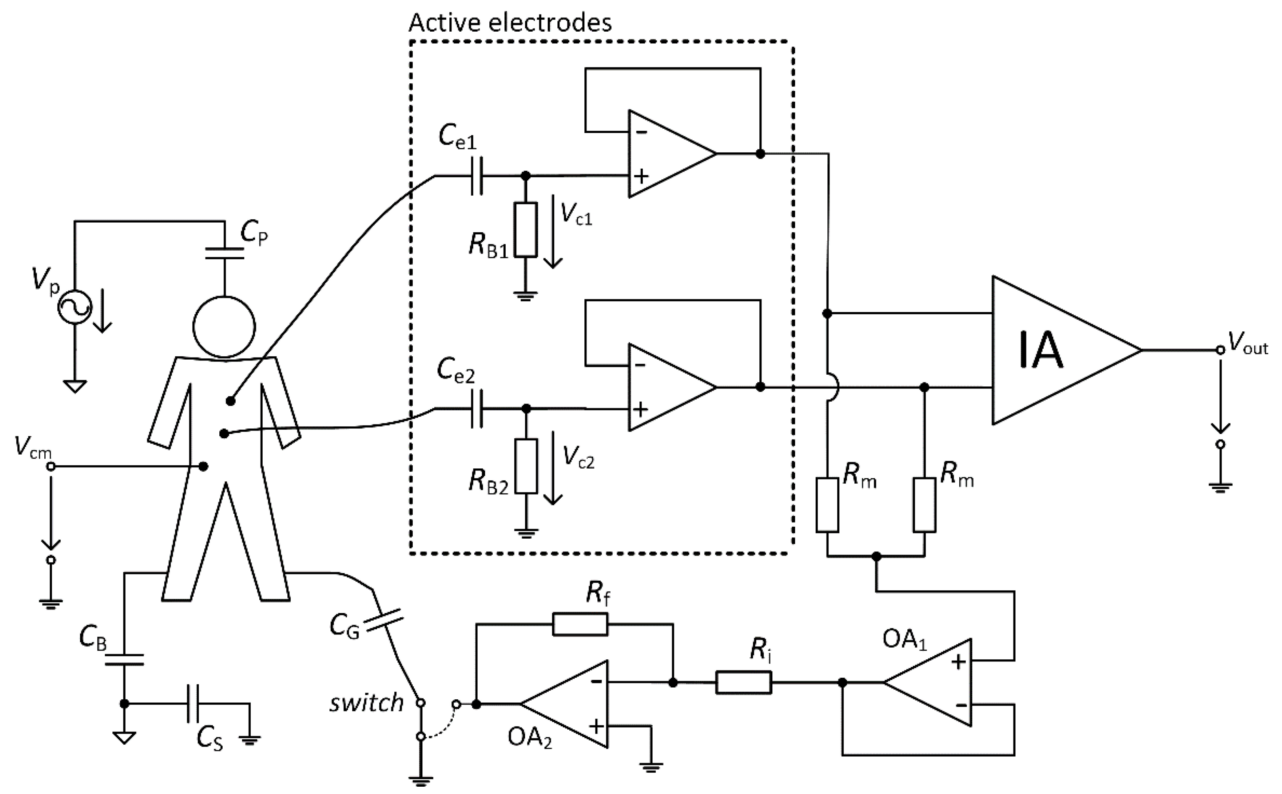

Figure 5. Electrical model depicting the power-line interference. 
Table 2. Values of coupling capacitances in the power-line and measured subject environment.

\begin{tabular}{cc}
\hline Variable & Value $[\mathrm{pF}]$ \\
\hline$C_{\mathrm{p}}$ & 2 \\
$C_{\mathrm{B}}$ & 200 \\
$C_{\mathrm{S}}$ & 200 \\
\hline
\end{tabular}

In general, the $\mathrm{Ag} / \mathrm{AgCl}$ electrodes are used for patient grounding to reduce commonmode noise. The grounding can be realized in two ways: 1 . direct connection of the electrode to the ground of the acquisition system; 2 . connection of the electrode to specialized DRL (Driven Right Leg) circuit to suppress the common-mode noise actively [7]. This connection decreases the value of $V_{\mathrm{cm}}$ common-mode voltage measured together with biosignal. The connection of such electrodes is not possible in the case of a capacitively coupled system. The contact grounding electrode has to be replaced by the capacitive noise suppression electrode (NSE). This capacitive electrode is also connected to the ground of the system [23] or to the output of the DRL circuit [24] in the same manner as the standard wet $\mathrm{Ag} / \mathrm{AgCl}$ electrode. These two options are selectable by a switch in Figure 5. The capacitance between the body and NSE is shown as $C_{\mathrm{G}}$ in the schematic.

Figure 6 shows the simplified model for suppressing $V_{\mathrm{cm}}$ when the NSE is connected directly to the ground of the acquisition system. Figure 6a shows the interference model, and Figure $6 \mathrm{~b}$ represents the schematic of this model. In this analysis, we are not dealing with the parameters of AEs because of their high impedance (when we assume the bias resistor in the range of gigaohms).

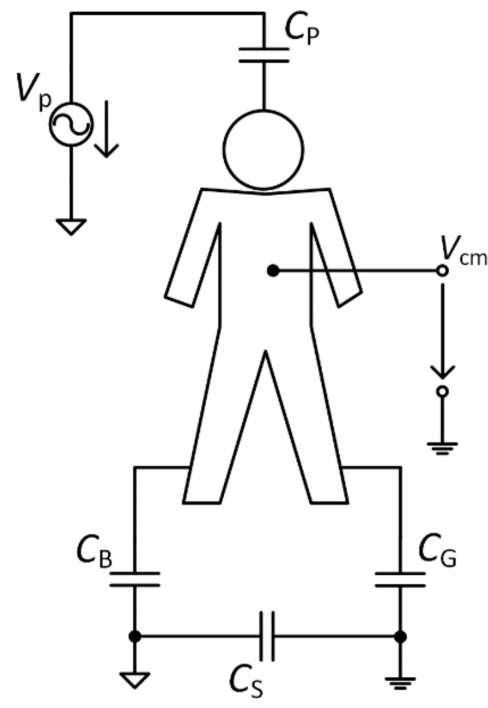

a)

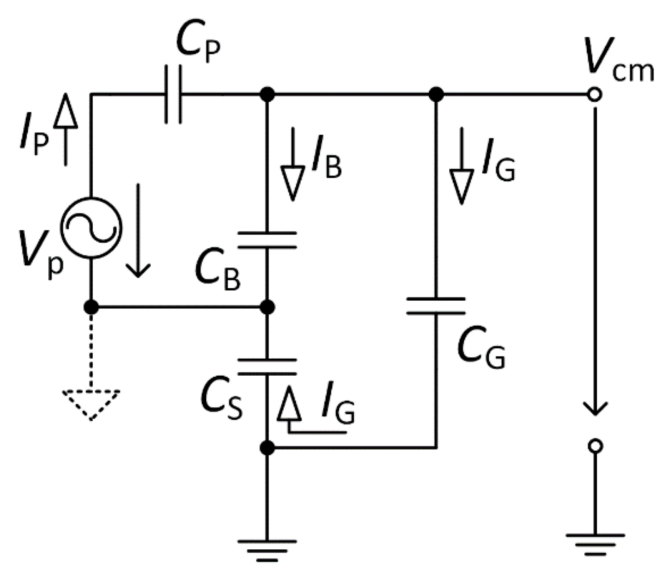

b)

Figure 6. Schematic circuit (a) and equivalent circuit for a common-mode voltage (b).

Based on the model, we can define the ratio between the $V_{\mathrm{cm}}$ common-mode voltage and $V_{\mathrm{P}}$ power-line source as

$$
\frac{V_{\mathrm{cm}}}{V_{\mathrm{p}}}=\frac{Z_{\mathrm{B}} Z_{\mathrm{G}}}{Z_{\mathrm{P}} Z_{\mathrm{B}}+Z_{\mathrm{P}} Z_{\mathrm{S}}+Z_{\mathrm{P}} Z_{\mathrm{G}}+Z_{\mathrm{S}} Z_{\mathrm{B}}+Z_{\mathrm{G}} Z_{\mathrm{B}}},
$$

where $Z_{\mathrm{B}}, Z_{\mathrm{P}}, Z_{\mathrm{S}}$, and $Z_{\mathrm{G}}$ are impedances of $C_{\mathrm{B}}, C_{\mathrm{P}}, C_{\mathrm{S}}$, and $C_{\mathrm{G}}$, respectively. According to that fact, we can derive equation as

$$
\frac{V_{\mathrm{cm}}}{V_{\mathrm{p}}}=\frac{C_{\mathrm{P}} C_{\mathrm{S}}}{C_{\mathrm{S}} C_{\mathrm{G}}+C_{\mathrm{G}} C_{\mathrm{B}}+C_{\mathrm{B}} C_{\mathrm{S}}+C_{\mathrm{P}} C_{\mathrm{E}}+C_{\mathrm{S}} C_{\mathrm{P}}} .
$$


Using Equation (5), we can state that with the increasing value of $C_{\mathrm{G}}$ the suppression of the $V_{\mathrm{cm}}$ also increases. In the case of infinity $C_{\mathrm{G}}$ capacitance $\left(C_{\mathrm{G}} \rightarrow \infty\right)$, the $V_{\mathrm{cm}}$ equals zero.

The grounding electrode size is usually more extensive than the active electrode size. We assume the capacitances are in the range of hundreds $\mathrm{pF}$ to a few $\mathrm{nF}$. As mentioned before, the $C_{P}$ capacitance changes with the measured subject's position within the measurement space. This capacitance is changing with the count of other devices connected to the same power network supplied by $V_{\mathrm{P}}$ and their distances from the measured subject [25]. The value of $C_{P}$ is lower while using a lower number of supplied devices. The values of $C_{B}$ and $C_{S}$ are considered constant in our analysis (we used values listed in Table 2). Figure 7 shows the graphical representation of Equation (5) with the usage of before mentioned values. We can see that the decrease of $V_{\mathrm{cm}}$ depends on the size of the capacitive grounding electrode and the capacitance between the subject and $V_{P}$ source.

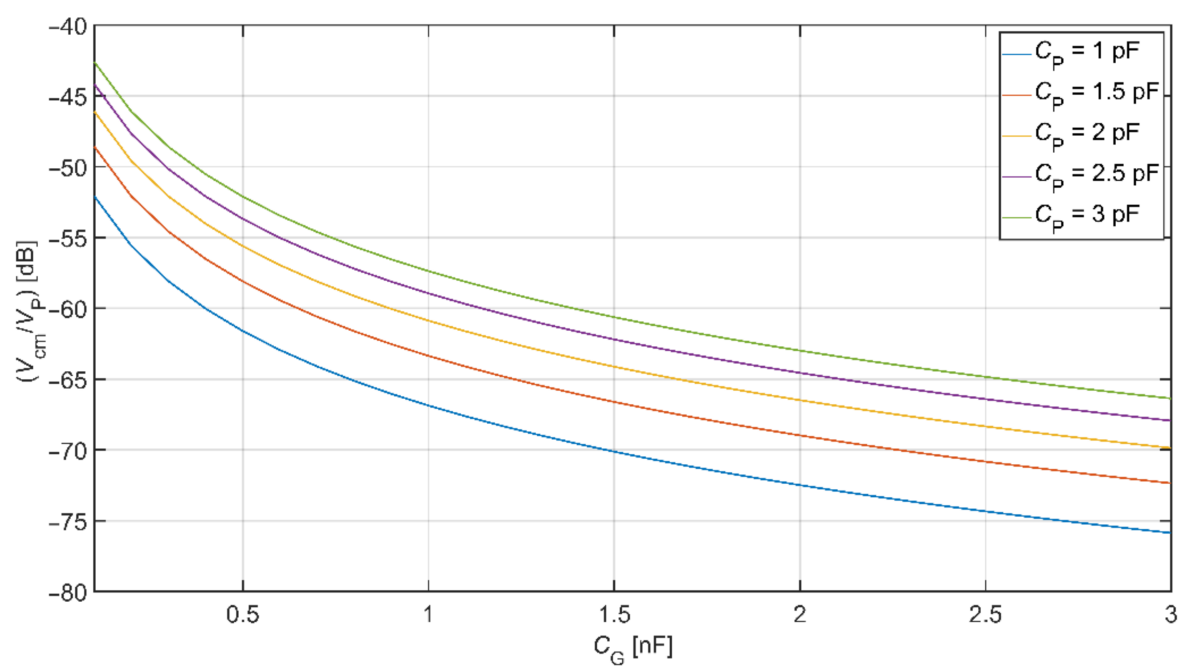

Figure 7. Common-mode voltage rejection for a system with noise suppression electrode (NSE) electrode connected to the system ground.

The interference model with a connected DRL circuit is shown in Figure 8. According to Figure 5 (case with a connected switch to the output of OA2), this schematic was created. Figure 6 presented a model where NSE is connected to the ground of the acquisition system, and parameters $\left(R_{\mathrm{B} 1}, R_{\mathrm{B} 2}, C_{\mathrm{e} 1}, C_{\mathrm{e} 2}\right)$ of AEs were neglected. We have to consider parameters of AEs under the analysis of the $V_{\mathrm{cm}}$ suppression using the DRL circuit because the DRL circuit inverts and amplifies the mean of AEs output signals. The total suppression of $V_{\mathrm{cm}}$ depends on the voltages acquired by active electrodes (shown in Figure 8 as $V_{\mathrm{c} 1}$ and $V_{\mathrm{c} 2}$ ) and on DRL circuit gain. Using the schematic presented in Figure 5, we can define the $G_{D R L}$ gain of the DRL circuit by

$$
G_{\text {DRL }}=-\frac{R_{\mathrm{f}}}{R_{\mathrm{i}}}
$$

and the $V_{\text {DRL }}$ shown in Figure 8 is defined by

$$
V_{\mathrm{DRL}}=G_{\mathrm{DRL}}\left(\frac{V_{\mathrm{c} 1}+V_{\mathrm{c} 2}}{2}\right)=-\frac{R_{\mathrm{f}}}{R_{\mathrm{i}}}\left(\frac{V_{\mathrm{c} 1}+V_{\mathrm{c} 2}}{2}\right) .
$$




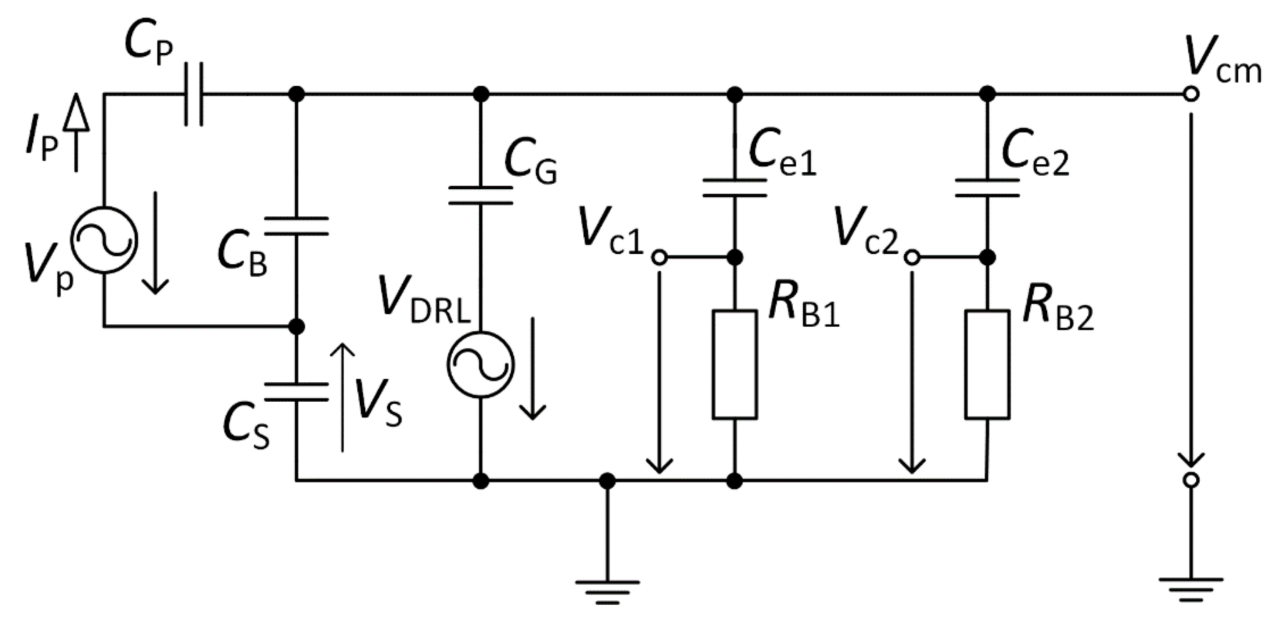

Figure 8. Equivalent schematic of an interference model for the system using a Driven Right Leg (DRL) circuit.

It is possible to define Equations (8)-(11) using Kirchhoff's laws, based on the model shown in Figure 8. A similar derivation was presented in [22].

$$
j \omega C_{\mathrm{P}}\left(V_{\mathrm{P}}-V_{\mathrm{cm}}-V_{\mathrm{S}}\right)=j \omega C_{\mathrm{B}}\left(V_{\mathrm{cm}}+V_{\mathrm{S}}\right)+j \omega C_{\mathrm{S}} V_{\mathrm{S}},
$$

$$
\begin{gathered}
j \omega C_{\mathrm{S}} V_{\mathrm{S}}=j \omega C_{\mathrm{G}}\left[V_{\mathrm{cm}}-\left(-\frac{R_{\mathrm{f}}}{R_{\mathrm{i}}}\left(\frac{V_{\mathrm{c} 1}+V_{\mathrm{c} 2}}{2}\right)\right)\right]+j \omega C_{\mathrm{e} 1}\left(V_{\mathrm{cm}}-V_{\mathrm{c} 1}\right)+j \omega C_{\mathrm{e} 2}\left(V_{\mathrm{cm}}-V_{\mathrm{c} 2}\right), \\
j \omega C_{\mathrm{e} 1}\left(V_{\mathrm{cm}}-V_{\mathrm{c} 1}\right)=\frac{V_{\mathrm{c} 1}}{R_{\mathrm{B} 1}} \\
j \omega C_{\mathrm{e} 2}\left(V_{\mathrm{cm}}-V_{\mathrm{c} 2}\right)=\frac{V_{\mathrm{c} 2}}{R_{\mathrm{B} 2}}
\end{gathered}
$$

The MATLAB language script was created to evaluate the $V_{\mathrm{cm}}$ value depending on $C_{G}$ capacitance and $G_{D R L}$ gain. Equations (8)-(11) were implemented in this script. The values of $C_{\mathrm{B}}, C_{\mathrm{P}}$, and $C_{\mathrm{S}}$ were set up according to Table $2, C_{\mathrm{e} 1}=C_{\mathrm{e} 2}=150 \mathrm{pF}$ and $R_{\mathrm{B} 1}=R_{\mathrm{B} 2}$ $=3 \mathrm{G} \Omega$. The result of this analysis is shown in Figure 9. It is seen that the value of $V_{\mathrm{cm}}$ is attenuating with the increasing value of $C_{\mathrm{G}}$ and $G_{\mathrm{DRL}}$.

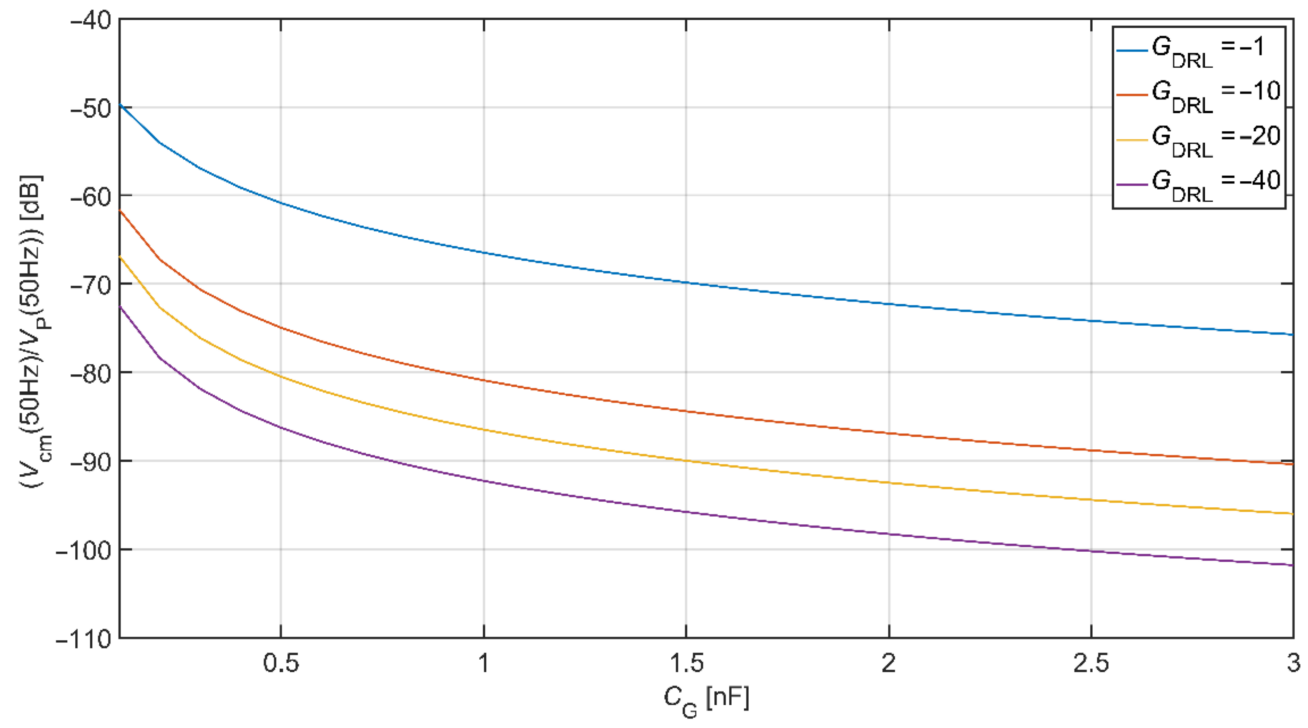

Figure 9. Common-mode voltage rejection for the system using a DRL circuit. 
The comparison of common-mode rejection depending on different DRL gain is shown in Figure 10. This graph is made for common-mode voltage at a frequency of $50 \mathrm{~Hz}$. Values of coupled capacitances between the subject and the power-line were set up according to Table 2 . In the analysis, we assume the value of $C_{\mathrm{e} 1}=C_{\mathrm{e} 2}=150 \mathrm{pF}$ and $R_{\mathrm{B} 1}=R_{\mathrm{B} 2}=3 \mathrm{G} \Omega$. This comparison shows that using the DRL circuit and its increasing gain also increases the system's common-mode voltage rejection. For example, if $C_{\mathrm{G}}=1 \mathrm{nF}$ and $G_{\mathrm{DRL}}=-40$, the suppression of common-mode voltage is $-60.88 \mathrm{~dB}$ and $-92.28 \mathrm{~dB}$ for electrodes connected to system ground and DRL circuit, respectively.

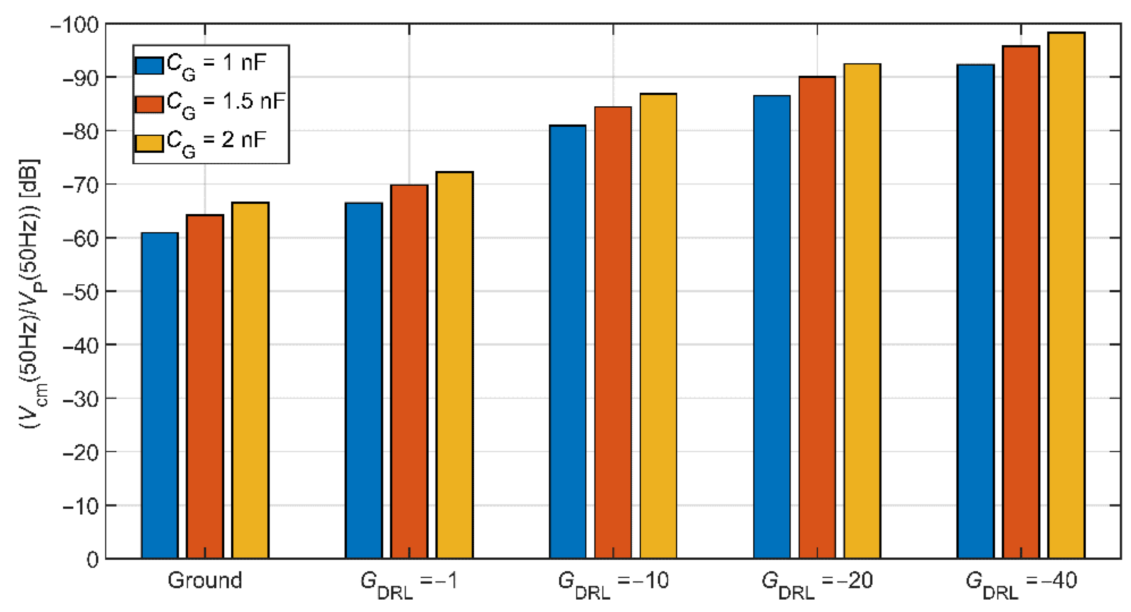

Figure 10. The comparison of common-mode rejection depending on different DRL gain.

Figure 11 represents the scheme of the designed acquisition system for measurement of capacitive ECG. The digital and analog parts can be identified in the schematic. The analog part uses an instrumentation amplifier (IA.) AD8421 (Analog Devices, Norfolk County, MA, USA) at the input and 4 OAs AD8642 (Analog Devices, Norfolk County, MA, USA). The analog part is supplied by $\pm 12 \mathrm{~V}$ bipolar voltage source. The IA deals with acquiring the signals that come from AEs. The OAs provide additional signal gain, filtration, and take part in the DRL circuit. The developed device allows choosing between the GND and the DRL for the NSE connection. The GDRL was set to the value of -39 . The digital part provides data digitalization and transmission to the PC. The 12-bit ADC (Analog to Digital Converter) LTC1296 (Linear Technology, Linear Technology, USA) with a $5 \mathrm{~V}$ reference was used for digitalization. The ATmega328P (Atmel, San Jose, CA, USA) was used as a control MCU. The gain of IA is 1 , and the gain of the successive operational amplifier is set to a value of 201.4. The sampling frequency was set to a value of $500 \mathrm{~Hz}$.

Three NSEs with the size $22 \mathrm{~cm} \times 75 \mathrm{~cm}$ and two AEs were placed onto the mattress to experimentally examine the dependency between the system's common-mode rejection and NSE size. The placement of electrodes is shown in Figure 12a. Similar electrode placement was used in previous papers dealing with monitoring of ECG during sleep [24,26-28]. NSEs are made from electroconductive fabric. This fabric is made from a fiber with a core from polyamide and a sheath from pure silver. The same fabric was used by Babušiak et al. [28]. The coupling capacitances between the subject body and electrodes are depicted in Figure 12b. These capacitances depend on the position of examined subject and clothes (dielectric) properties. The total capacitance between the subject and NSEs can be defined as the sum of capacitances connected in parallel. In the case of closed switches $S_{1}, S_{2}$, and $\mathrm{S}_{3}$, the total capacitance is calculated as

$$
C_{\mathrm{G}}=\mathrm{C}_{\mathrm{G} 1}+\mathrm{C}_{\mathrm{G} 2}+\mathrm{C}_{\mathrm{G} 3} \text {. }
$$




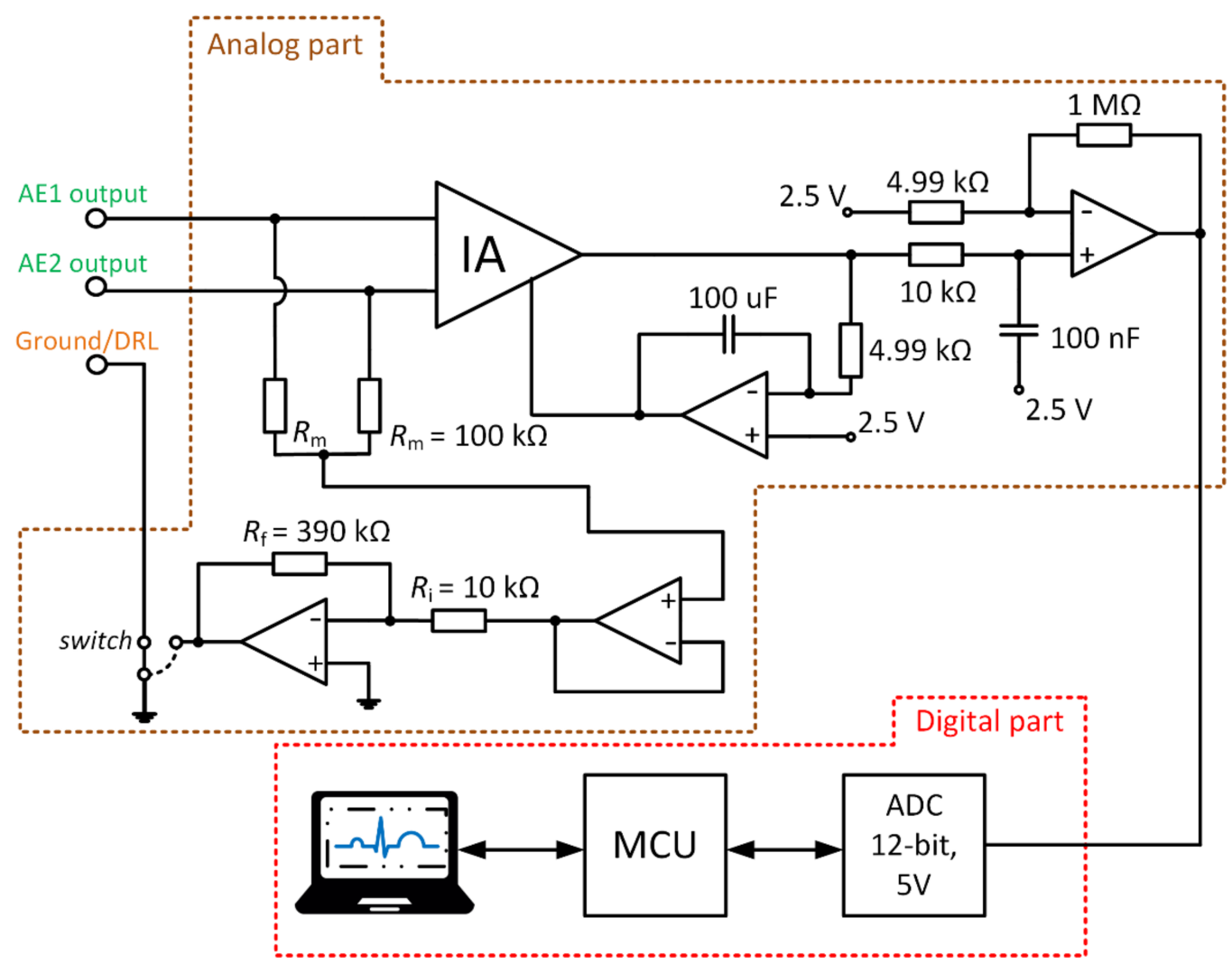

Figure 11. Block scheme of developed electrocardiography (ECG) system.

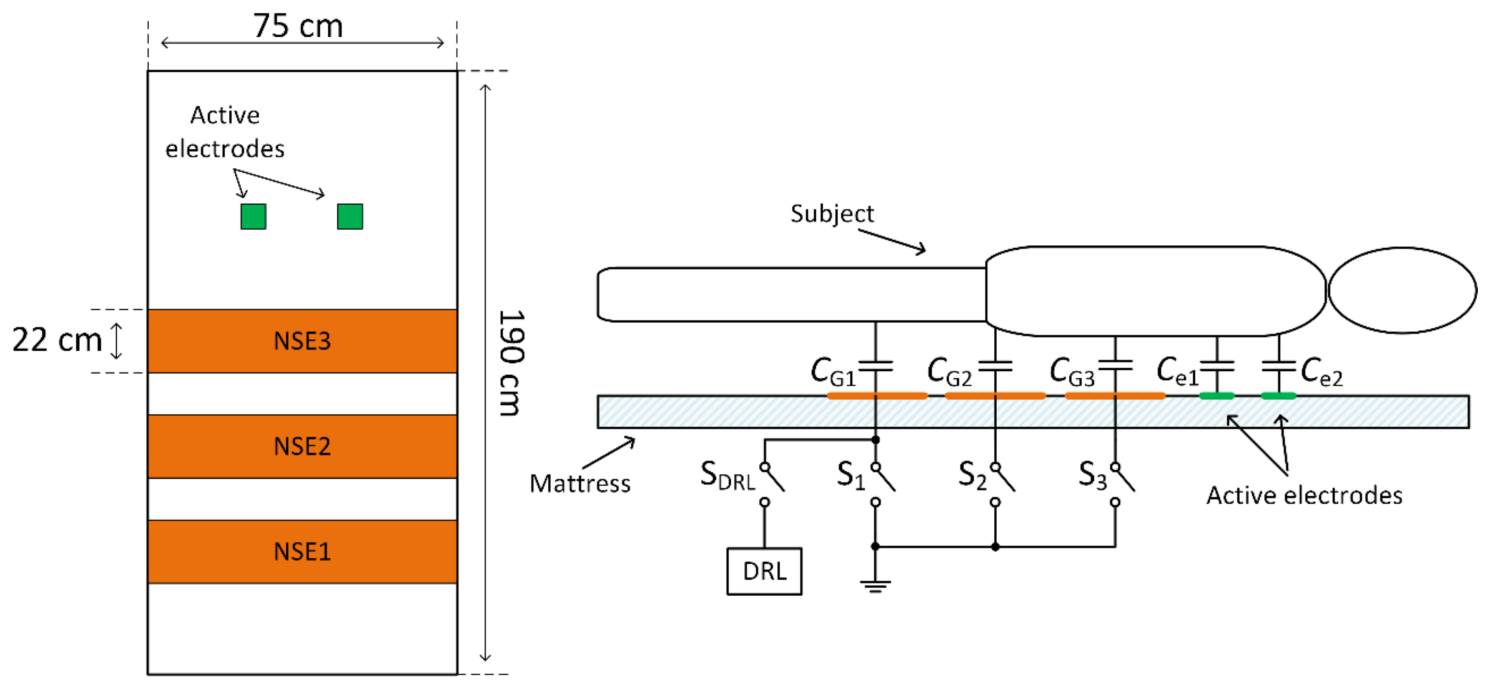

a)

b)

Figure 12. Placement of electrodes on the bedsheet (a), and a model of coupling capacitances between the subject and electrodes (b).

The upper presented theory and the as-designed capacitive system are verified by simulation in TINA TI (Texas Instruments, Inc., Dallas, TX, USA). The equivalent model is shown in Figure 13. In the simulation, the macro models of used components are provided by the producer. All parameters are set up according to the capacitive ECG system showed in Figure 11. Capacitances listed in Table 2 are included in our simulation. The $V_{\mathrm{P}}$ is 
configured as a sine-wave voltage generator with a frequency of $50 \mathrm{~Hz}$ and an amplitude of $230 \mathrm{~V}$ (power supply in the EU). The $V_{\mathrm{P}}$ is used as a source of common-mode voltage. The value of $C_{G}$ capacitance is set up to the value of $1 \mathrm{nF}$. The $V_{\mathrm{ECG}}$ source generates an ECG signal acquired by bipolar measurement of ECG from the subject's back using standard disposable electrodes. The placement of disposable electrodes corresponds to the position of the electrodes used in our bed (Figure 12a). The Biopac MP36 acquisition unit (BIOPAC Systems, Goleta, CA, USA) was used for acquiring ECG samples for the $V_{\text {ECG }}$ source. It was set up hardware band-pass filter with corner frequencies $0.05 \mathrm{~Hz}$ and $150 \mathrm{~Hz}$, and sampling frequency was set up to the value of $500 \mathrm{~Hz}$. The waveforms of $V_{\mathrm{ECG}}$ and $V_{\mathrm{P}}$ are shown in Figure 14.

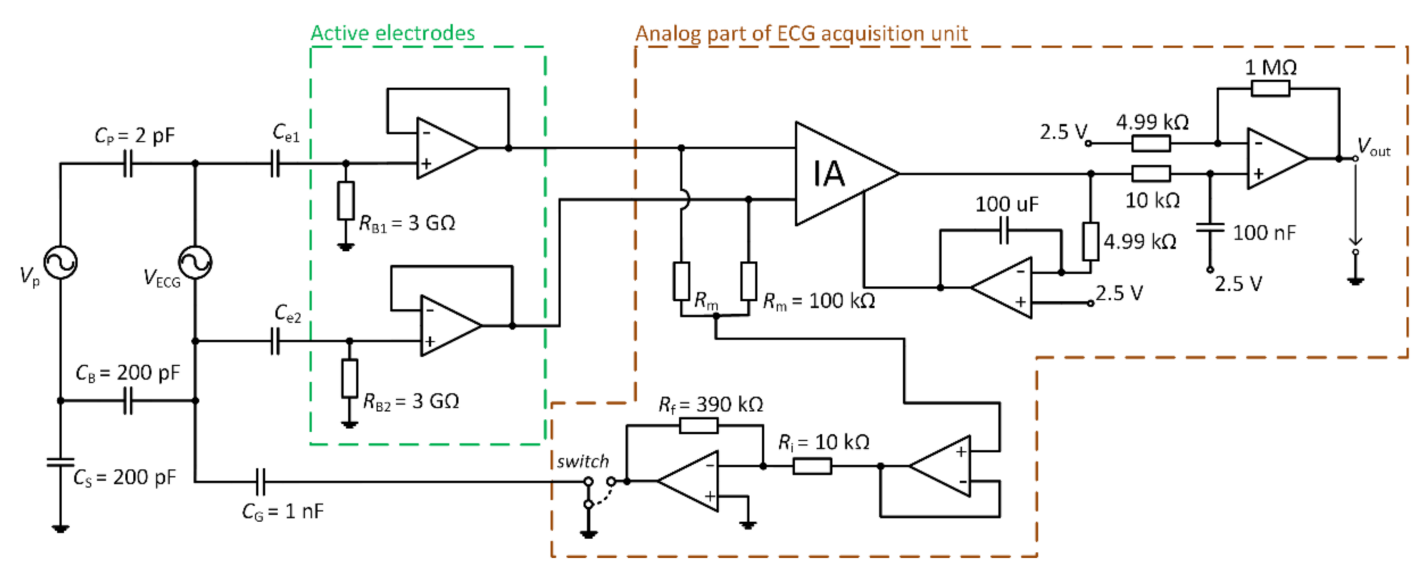

Figure 13. Schematic of the simulation model.

(a)

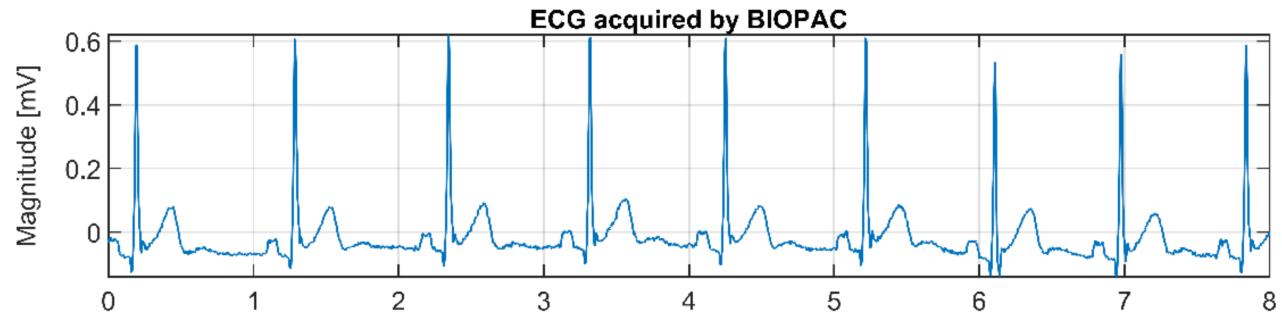

(b)

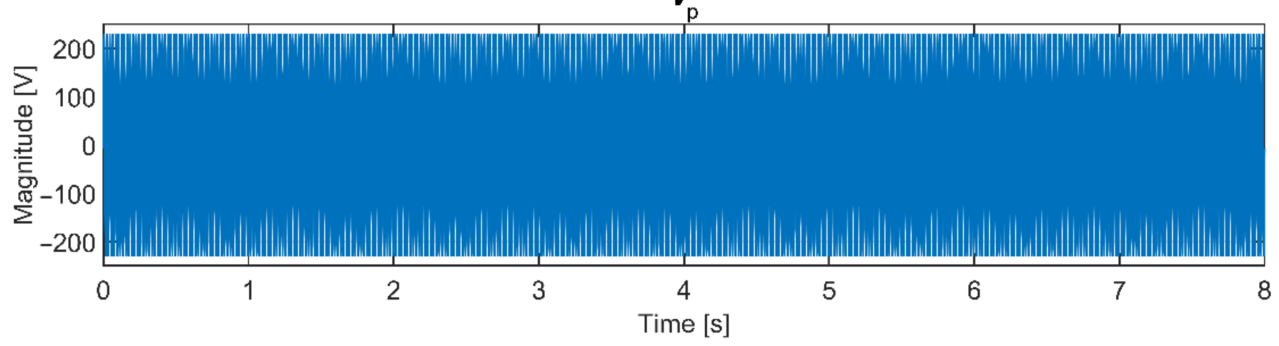

Figure 14. The ECG signal waveform (a) and the power-line voltage waveform (b) used in the simulation.

\section{Results and Discussion}

The verification of the presented theory was done by a simulation on the model presented in Figure 13. The first series of the simulation uses the same values of AEs coupling capacitances $\left(C_{\mathrm{e} 1}=C_{\mathrm{e} 2}=150 \mathrm{pF}\right)$. The $V_{\text {out }}$ output signals of NSE connected to the ground and the DRL output are shown in Figure 15. As seen from this figure, the commonmode voltage is effectively suppressed in both cases when the coupling capacitances are identical. 


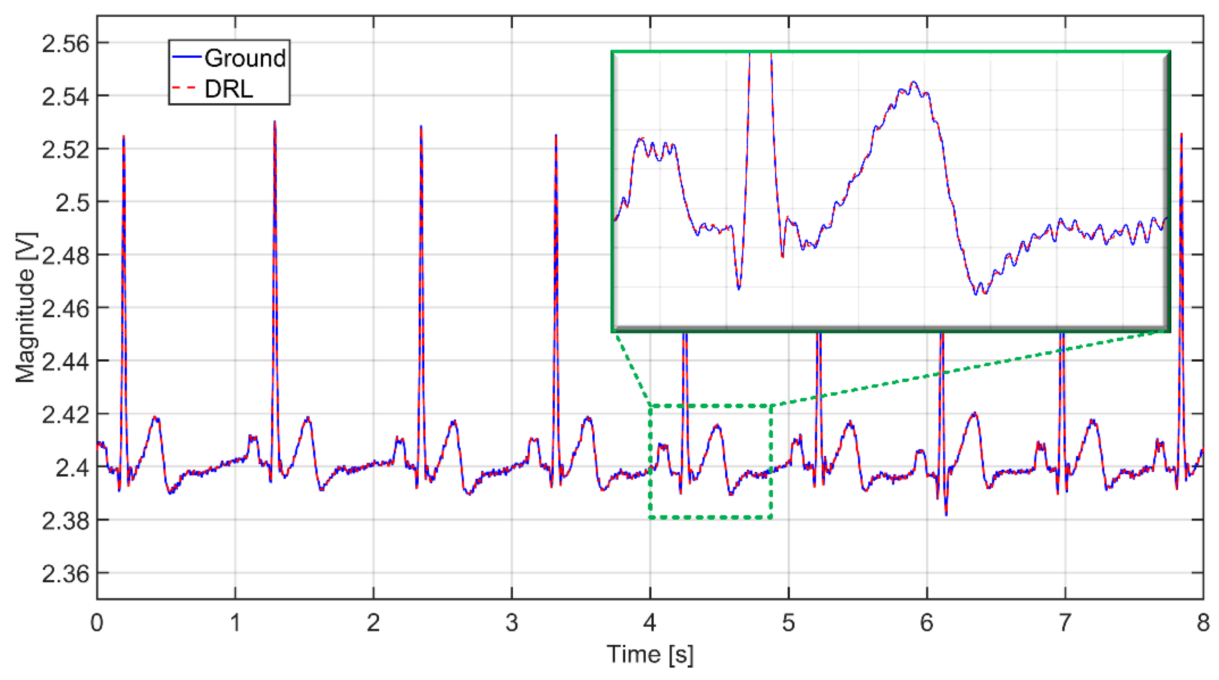

Figure 15. The output signals from simulation while using the same coupling capacitances $\left(C_{\mathrm{e} 1}=\right.$ $C_{\mathrm{e} 2}=150 \mathrm{pF}$ ) at the input in two scenarios: The NSE connected to the ground (solid blue), and NSE connected to the output of DRL (dashed red).

In practice, it is almost impossible to ensure the same values of input coupling capacitances. This fact is caused by local differences in the thickness and composition of dielectric material (clothes) and the electrode's pressure. These differences lead to the different gain of each electrode [16]. According to Peng et al. [29], the differences between the input $\mathrm{AE}$ capacitances can be doubled during the measurement. We adjusted the simulation parameters to fulfill mentioned assumption: the $C_{\mathrm{e} 1}$ and $C_{\mathrm{e} 2}$ are set up to $150 \mathrm{pF}$ and $75 \mathrm{pF}$, respectively. A different gain of the AEs leads to an unequal value of the common-mode voltage at the input of IA (see Figure 13). The successive operational amplifier further amplifies the common-mode voltage from the IA output. The simulated output signals corresponding to scenarios with different switch positions are shown in Figure 16. We can see that the unequal gain of AEs caused a relatively high value of the common-mode voltage $(50 \mathrm{~Hz})$ in the acquired signal. We can also see that the common-mode voltage is higher when the NSE is connected to the ground than connected to DRL output. The higher $V_{\mathrm{cm}}$ value or higher difference of input coupling capacitances can cause the saturation of the analog amplifiers or saturation of ADC input. In practice, it is necessary to prevent this kind of problem by sufficient rejection of the $V_{\mathrm{cm}}$ voltage or balancing input capacitances [30].

A series of experiments were performed to support the results from the simulation. The ECG system in Figure 11 and the electrode placement in Figure 12 are used in the experiments. The measured subject is lying on the mattress, while the bipolar capacitive ECG is measured from the back. A cotton T-shirt and a cotton tracksuit were used as upper-body and lower-body clothes, respectively.

The effectivity of the NSE connected to system ground in common-mode rejection was examined at first. All three NSEs are not connected to the system ground at the beginning of the measurement (beginning of signal in Figure 17), and then they are gradually connected to the ground (rest of Figure 17). The ADC input saturation is observed in situations with unconnected NSEs and with one NSE connected due to a high level of common-mode noise. The saturation is not visible when at least two electrodes are connected. The common-mode rejection increases with an increasing number of connected NSEs. 


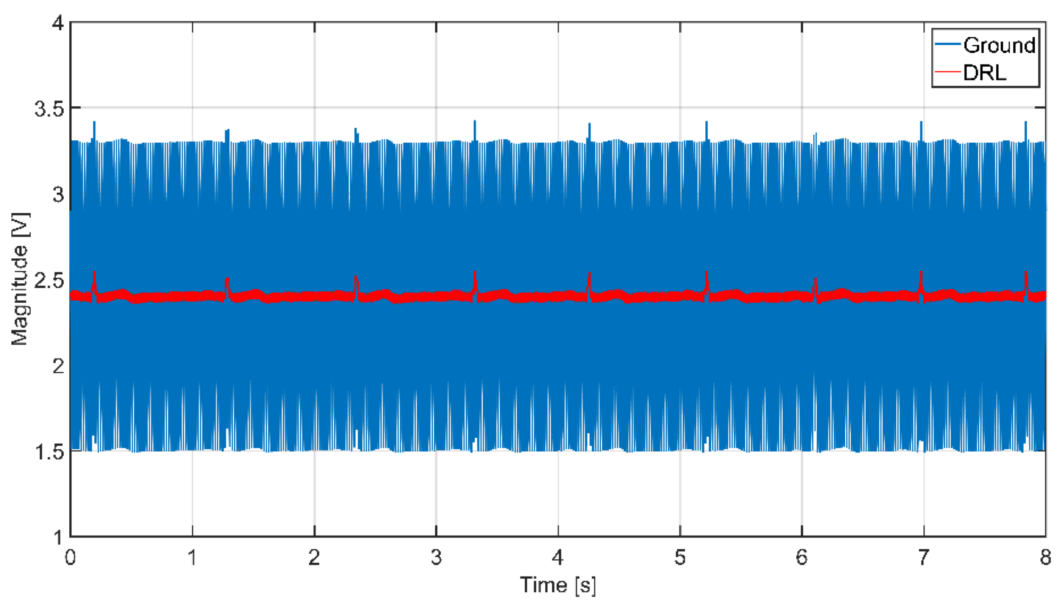

Figure 16. The output signals from simulation while using different coupling capacitances $\left(C_{\mathrm{e} 1}=150\right.$ $\mathrm{pF}, \mathrm{C}_{\mathrm{e} 2}=75 \mathrm{pF}$ ) at the input in two scenarios: The NSE connected to the ground (solid blue), and NSE connected to the output of DRL (solid red).

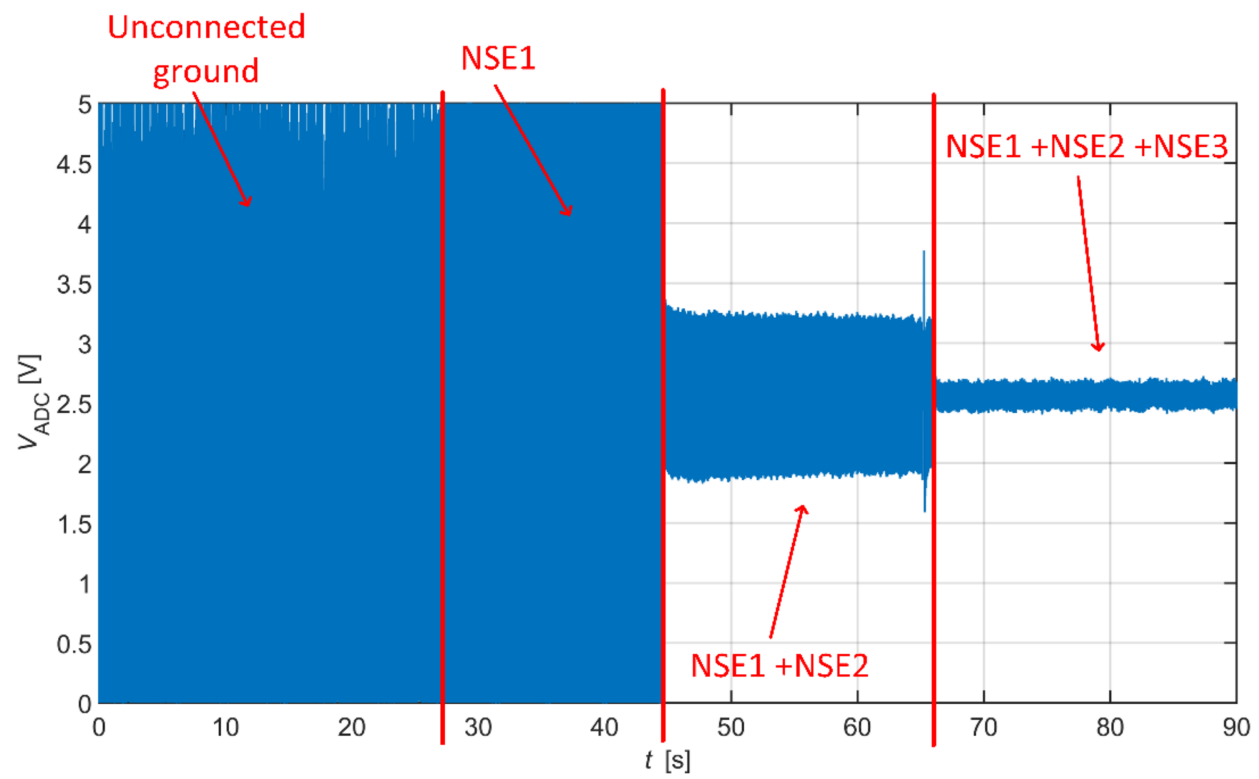

Figure 17. Capacitive ECG with gradually connected grounding electrodes.

As we already stated, the use of AEs is sufficient to measure ambulatory ECG in the frequency range from $0.67 \mathrm{~Hz}$ to $40 \mathrm{~Hz}$, so the resulting signal from Figure 17 is filtered by this digital band-pass filter. The filter attenuation in bandstop is $80 \mathrm{~dB}$. The filtered data are shown in Figure 18. The filtered data points to the fact that the system without grounding is saturated, and it is impossible to acquire ECG data. The ECG signal acquired by the system using one NSE (only NSE1) is recognizable, but its quality is shallow. The quality of measured ECG is better when using two and three NSEs. 
(a) $\Xi 40$

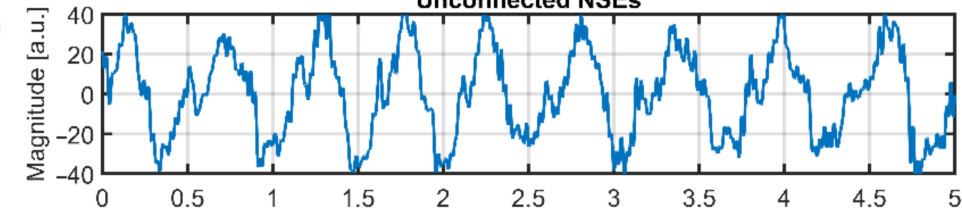

(b)

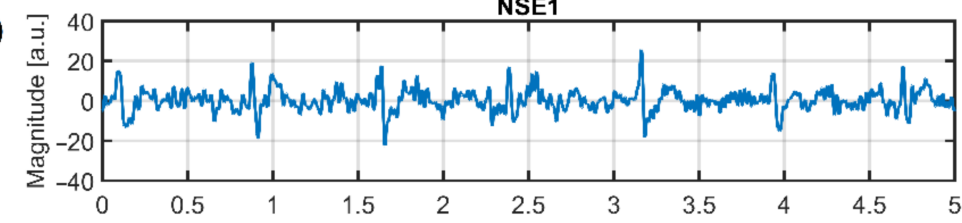

(c)

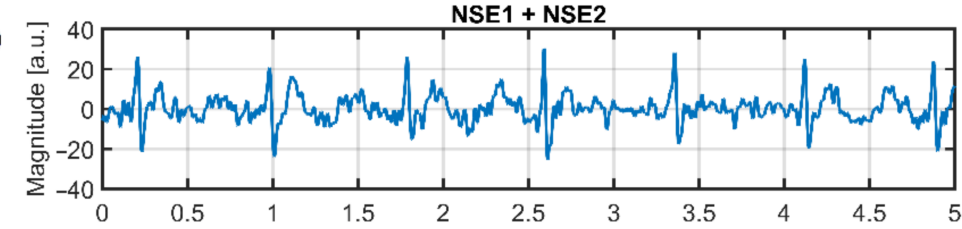

(d)

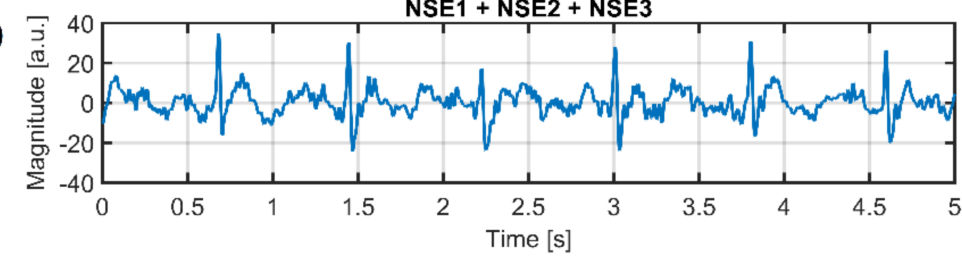

Figure 18. Filtered ECG data with gradually connected grounding electrodes-no grounding electrode (a), one grounding electrode (b), two grounding electrodes (c), and three grounding electrodes (d).

An extensive area of the grounding electrode made of conductive textile causes a high cost of the electrode as well as the whole system. The DRL circuit is an alternative for common-mode noise reduction in conventional and capacitive systems. In the presented theory, the DRL is more effective in common-mode noise suppression than grounding, as shown in Figure 10.

The verification of the DRL effectivity is done by measurement using the same system in Figure 11. The NSE1 is connected to the output of the DRL circuit (see Figure 12). The NSE2 and NSE3 are unconnected. The gain of the DRL circuit is -39 . The raw and filtered ECG data are shown in Figure 19. The R peaks are fully recognizable in the ECG signal even if only one NSE is used.

The comparison of power spectral densities of the signal acquired by the capacitive system using passive ground and DRL with the same NSE (position of NSE1 electrode) is shown in Figure 20. The difference between the power at a frequency of $50 \mathrm{~Hz}$ reaches $46.3 \mathrm{~dB}$. The comparison also shows that the noise is repeated at the multiples of power-line frequency when using a grounding electrode.

The following table summarizes the power of power-line noise $(50 \mathrm{~Hz})$ in the resulting ECG signal when using different noise suppression techniques and the number of NSE. The names of NSE are adapted from Figure 12. 
(a)

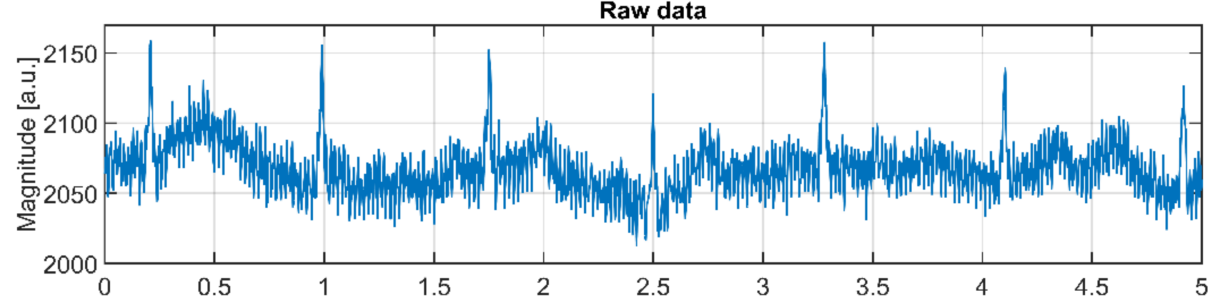

(b)

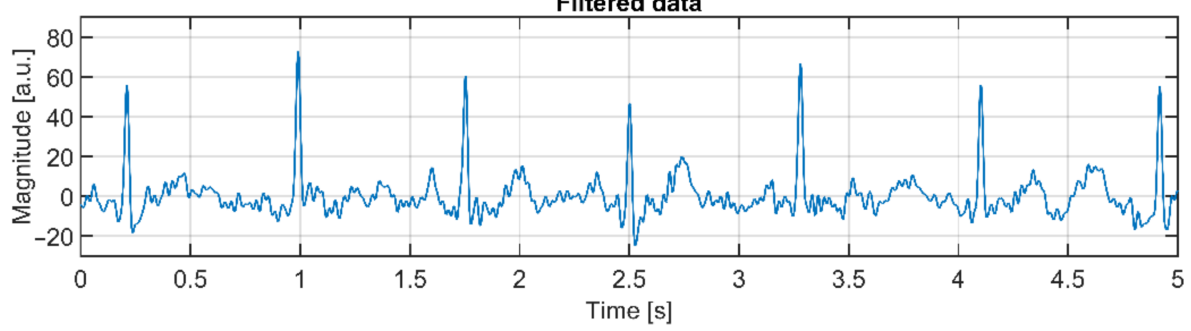

Figure 19. Raw ECG signal (a) and filtered signal (b) acquired by the capacitive system using the DRL electrode.

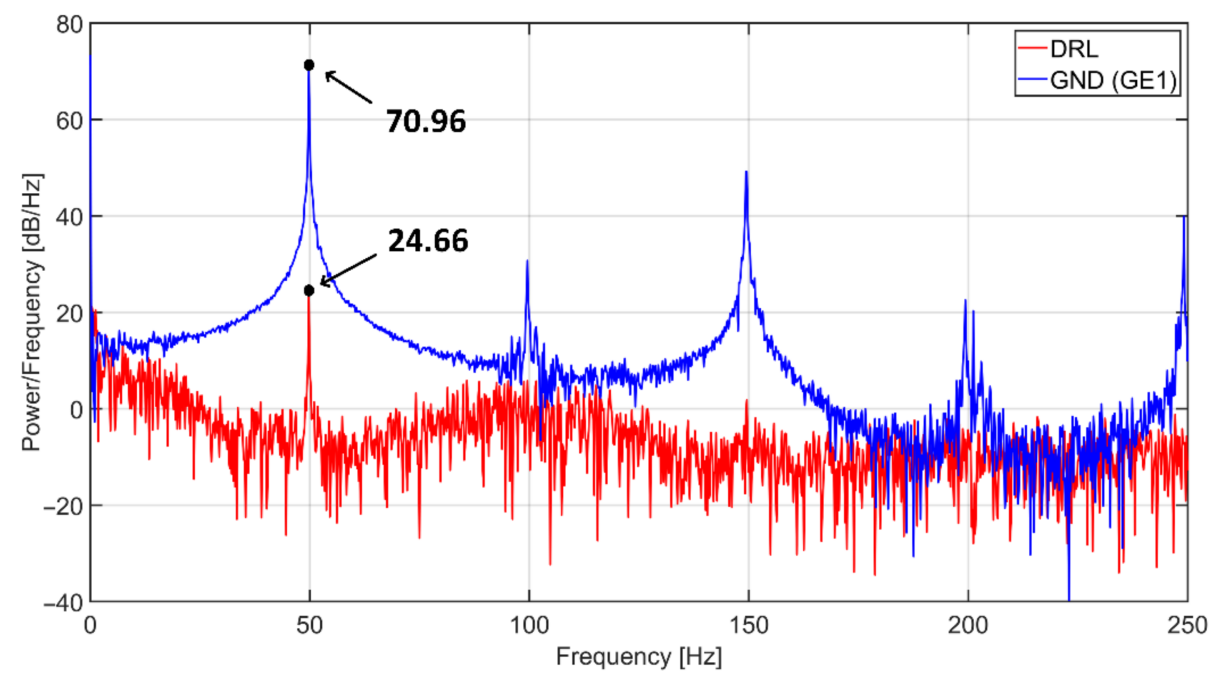

Figure 20. Power spectral densities of capacitive ECG signal using grounding (blue) and DRL (red) electrode.

\section{Conclusions}

The article was focused on analyzing a system for capacitive measurement of biosignals. In this work, we compared two methods for suppression of common-mode voltage in acquired data by using grounding and DRL electrode. We created the equivalent models describing the power-line's interference with the subject and the acquisition system (Figures 5-8). The models were analyzed in detail by simulations. The models were verified by measurements of capacitive ECG with a living subject lying on the mattress. Although some authors already presented the effect of grounding and DRL circuit on noise suppression, we provide a relevant comparison of these two methods in one article. The suppression methods are experimentally evaluated using one acquisition system, keeping the same condition of measurement. We found out that with the increasing size of the grounding electrode, the reduction of common-mode voltage also increases (Figure 17) according to theoretical assumption. Unfortunately, the large grounding electrode increases the manufacturing cost of the capacitive system due to expensive conductive fabrics. A DRL electrode is a powerful alternative to a grounding electrode. It provides better common-mode rejection (Table 3) while using a smaller electrode area. 
Table 3. The common-mode power of different noise suppression methods.

\begin{tabular}{cccc}
\hline $\begin{array}{c}\text { Noise Suppression } \\
\text { Method }\end{array}$ & Electrodes in Use & $\begin{array}{c}\text { Active Electrode } \\
\text { Area }\left[\mathbf{c m}^{2}\right]\end{array}$ & $\begin{array}{c}\text { Power of Noise } \\
\text { at 50 Hz } \mathbf{~ d B ]}\end{array}$ \\
\hline \multirow{2}{*}{ Grounding } & NSE1 & 1650 & 70.96 \\
& NSE1 + NSE2 & 3300 & 59.13 \\
& NSE1 + NSE2 + NSE3 & 4950 & 43.44 \\
\hline DRL & NSE1 & 1650 & 24.66 \\
\hline
\end{tabular}

Author Contributions: Conceptualization, methodology, and writing—original draft preparation, T.B.; writing-review and editing, supervision, B.B.; writing-review and editing, S.B.; methodology, M.L.; formal analysis, M.S. All authors have read and agreed to the published version of the manuscript.

Funding: This research was funded by the Slovak Research and Development Agency, grant number APVV-18-0167 and grant number APVV-16-0190.

Institutional Review Board Statement: Not applicable.

Informed Consent Statement: Patient consent was waived due to the participant is one of the authors.

Data Availability Statement: The data presented in this study are available on request from the corresponding author.

Conflicts of Interest: The authors declare no conflict of interest.

\section{References}

1. Vlach, K.; Kijonka, J.; Jurek, F.; Vavra, P.; Zonca, P. Capacitive biopotential electrode with a ceramic dielectric layer. Sens. Actuators B Chem. 2017, 245, 988-995. [CrossRef]

2. Sun, Y.; Yu, X.B. Capacitive Biopotential Measurement for Electrophysiological Signal Acquisition: A Review. IEEE Sens. J. 2016, 16, 2832-2853. [CrossRef]

3. Asl, S.N.; Ludwig, F.; Schilling, M. Noise properties of textile, capacitive EEG electrodes. Curr. Dir. Biomed. Eng. 2015, 1, 34-37. [CrossRef]

4. Babušiak, B.; Borik, S.; Balogova, L. Textile electrodes in capacitive signal sensing applications. Meas. J. Int. Meas. Confed. 2018, 114, 69-77. [CrossRef]

5. Peng, S.; Xu, K.; Chen, W. Comparison of Active Electrode Materials for Non-Contact ECG Measurement. Sensors 2019, 19, 3585. [CrossRef]

6. Rachim, V.P.; Chung, W.-Y. Wearable Noncontact Armband for Mobile ECG Monitoring System. IEEE Trans. Biomed. Circuits Syst. 2016, 10, 1112-1118. [CrossRef]

7. Webster, J.G. Medical Instrumentation: Application and Design; Wiley: New York, NY, USA, 1998.

8. Lim, Y.G.; Chung, G.S.; Park, K.S. Capacitive driven-right-leg grounding in Indirect-contact ECG measurement. In Proceedings of the 2010 Annual International Conference of the IEEE Engineering in Medicine and Biology, Buenos Aire, Argentina, 30 August-4 September 2010; pp. 1250-1253.

9. Xu, J.; Mitra, S.; Matsumoto, A.; Patki, S.; Van Hoof, C.; Makinwa, K.A.A.; Yazicioglu, R.F. A Wearable 8-Channel Active-Electrode EEG/ETI Acquisition System for Body Area Networks. IEEE J. Solid State Circuits 2014, 49, 2005-2016. [CrossRef]

10. Xu, J.; Busze, B.; Van Hoof, C.; Makinwa, K.A.A.; Yazicioglu, R.F. A 15-Channel Digital Active Electrode System for MultiParameter Biopotential Measurement. IEEE J. Solid State Circuits 2015, 50, 2090-2100. [CrossRef]

11. Mahajan, R.; Morshed, B.I. Performance analysis of a DRL-less AFE for battery-powered wearable EEG. Meas. J. Int. Meas. Confed. 2016, 90, 583-591. [CrossRef]

12. Spinelli, E.; Haberman, M. Insulating electrodes: A review on biopotential front ends for dielectric skin-electrode interfaces. Physiol. Meas. 2010, 31, S183-S198. [CrossRef]

13. Portelli, A.J.; Nasuto, S.J. Design and Development of Non-Contact Bio-Potential Electrodes for Pervasive Health Monitoring Applications. Biosensors 2017, 7, 2. [CrossRef]

14. Chi, Y.M.; Wang, Y.-T.; Wang, Y.; Maier, C.; Jung, T.-P.; Cauwenberghs, G. Dry and Noncontact EEG Sensors for Mobile Brain-Computer Interfaces. IEEE Trans. Neural Syst. Rehabil. Eng. 2012, 20, 228-235. [CrossRef]

15. Spinelli, E.; Haberman, M.; García, P.; Guerrero, F. A capacitive electrode with fast recovery feature. Physiol. Meas. 2012, 33, 1277-1288. [CrossRef]

16. Bednár, T.; Babušiak, B.; Smondrk, M.; Cap, I.; Borik, S. The impact of active electrode guard layer in capacitive measurements of biosignals. Measurement 2021, 171, 108740. [CrossRef] 
17. Bednár, T.; Babušiak, B. Measurement of capacitive coupled ECG from the car seat. Transp. Res. Procedia 2019, 40, 1260-1265. [CrossRef]

18. Hou, Z.; Xiang, J.; Dong, Y.; Xue, X.; Xiong, H.; Yang, B. Capturing Electrocardiogram Signals from Chairs by Multiple Capacitively Coupled Unipolar Electrodes. Sensors 2018, 18, 2835. [CrossRef]

19. Lee, J.S.; Heo, J.; Lee, W.K.; Lim, Y.G.; Kim, Y.H.; Park, K.S. Flexible Capacitive Electrodes for Minimizing Motion Artifacts in Ambulatory Electrocardiograms. Sensors 2014, 14, 14732-14743. [CrossRef]

20. Shafti, A.; Manero, R.B.R.; Borg, A.M.; Althoefer, K.; Howard, M.J. Embroidered Electromyography: A Systematic Design Guide. IEEE Trans. Neural Syst. Rehabil. Eng. 2016, 25, 1472-1480. [CrossRef]

21. Winter, B.B.; Webster, J.G. Driven-right-leg circuit design. IEEE Trans. Biomed. Eng. 1983, 30, 62-66. [CrossRef]

22. Ko, K.K.; Yong, K.L.; Kwang, S.P. Common mode noise cancellation for electrically non-contact ECG measurement system on a chair. Annu. Int. Conf. IEEE Eng. Med. Biol. Proc. 2005, 7, 5881-5883.

23. Singh, R.K.; Sarkar, A.; Anoop, C.S. A health monitoring system using multiple non-contact ECG sensors for automotive drivers. Conf. Rec. IEEE Instrum. Meas. Technol. Conf. 2016, 2016, 1-6. [CrossRef]

24. Babušiak, B.; Borik, S.; Smondrk, M.; Janousek, L. Smart Sheet Design for Electrocardiogram Measurement. Adv. Hum. Factors Bus. Manag. Train. Educ. 2019, 1011,507-517. [CrossRef]

25. Chimene, M.; Pallas-Areny, R. A comprehensive model for power line interference in biopotential measurements. IEEE Trans. Instrum. Meas. 2000, 49, 535-540. [CrossRef]

26. Lim, Y.G.; Kim, K.K.; Park, K.S. ECG Recording on a Bed during Sleep Without Direct Skin-Contact. IEEE Trans. Biomed. Eng. 2007, 54, 718-725. [CrossRef]

27. Chamadiya, B.; Mankodiya, K.; Wagner, M.; Nasreddine, R.; Hofmann, U. Non-contact, non-obtrusive electrocardiography in clinical environements. In Proceedings of the 5th International ICST Conference on Pervasive Computing Technologies for Healthcare, Dublin, Ireland, 23-26 May 2011. [CrossRef]

28. Babušiak, B.; Šmondrk, M.; Balogová, L.; Gála, M. Mattress Topper with Textile ECG Electrodes. J. Vlakna Textil. 2020, 3, 25-28.

29. Peng, G.; Ignjatovic, Z.; Bocko, M.F. Preamplifiers for non-contact capacitive biopotential measurements. In Proceedings of the 2013 35th Annual International Conference of the IEEE Engineering in Medicine and Biology Society (EMBC), Osaka, Japan, 3-7 July 2013; pp. 1482-1485. [CrossRef]

30. Chen, M.; Wang, J.; Anzai, D.; Fischer, G.; Kirchner, J. Common-Mode Noise Reduction in Noncontact Biopotential Acquisition Circuit Based on Imbalance Cancellation of Electrode-Body Impedance. Sensors 2020, 20, 7140. [CrossRef] [PubMed] 